\title{
De verhouding tussen psychiatrie en (straf)recht
}

\author{
A.W.M. Mooij ${ }^{*}$
}

\section{Inleiding}

De forensische psychiatrie ofwel gerechtelijke psychiatrie beweegt zich op het grensgebied van psychiatrie en recht, en voorzover het de forensische strafrechtelijke psychiatrie betreft, is dit het grensgebied tussen psychiatrie en strafrecht.

Het strafrecht heeft deels tot inhoud de strafbaarstelling van menselijke gedragingen, de redengeving van de strafbaarstelling van de gedraging procedurele bepalingen, voorwaarden waaraan voldaan moet zijn wil er van strafwaardigheid sprake zijn, procedurele bepalingen etc. Het strafrecht beschouwt de mens in aanleg als aanspreekbaar op zijn gedrag, zodat deze daarop feitelijk aangesproken kan worden en daarvoor in een nader te bepalen zin verantwoordelijk gehouden kan worden. Deze veronderstelling aangaande de mens als een wezen dat verantwoordelijk gehouden kan worden voor zijn daden is een basisvooronderstelling van het strafrecht, en vermoedelijk van het moderne recht in zijn geheel. Met deze vooronderstelling is de gedachte verbonden dat de mens een vermogen heeft over zichzelf te beschikken, een soort zelfbeschikkingsmacht kan uitoefenen, ofwel een zekere vorm van autonomie heeft.

Het is immers niet redelijk iemand verantwoordelijk voor zijn daden te houden als hij niet zelf de actor hiervan is ofwel niet oorsprong van dit handelen is. Met deze veronderstelling is tevens de gedachte verbonden dat de mens die handelt min of meer weet wat hij doet. Het is immers evenmin redelijk om iemand die niet weet wat hij doet, in de strikte zin dat hij niet weten kan wat hij doet, verantwoordelijk te houden voor zijn gedrag. Verantwoordelijkheid, autonomie en vermogen tot inzicht zijn dus elkaar aanvullende be-

* Zenuwarts, verbonden aan het het Pieter Baan Centrum te Utrecht, hoogleraar te Utrecht Universiteit Utrecht en bijzonder hoogleraar forensische psychiatrie Rijksuniversiteit Groningen 
grippen die uit één betekenisveld stammen, en aldus een samenhang vertonen. Deze begrippen vormen gezamenlijk, zij het niet uit-puttend, de kern van wat men het juridische persoonsbegrip of mensbeeld kan noemen. Daarmee is tevens gezegd dat het recht teruggaat op dan wel gegrond is in een mensbeeld, te weten een visie op de menselijke werke-lijkheid.

De psychiatrie heeft op het eerste gezicht een andere invalshoek. Zij richt zich op stoornissen die het menselijk handelen beïnvloeden en bepalen zoals psychotische verschijnselen of beperkingen in de persoonlijkheid, de zogenaamde persoonlijkheidsstoornissen. Daaraan ligt de gedachte ten grondslag dat menselijk gedrag bepaald wordt door deels externe deels interne factoren. Daarbij wordt de grens tussen gestoord en niet gestoord soms als scherp en soms als vloeiend gezien. Er zijn enerzijds verschijnselen die uiting zijn van een onmiskenbare psychiatrische stoornis (zoals wanen en hallucinaties) waar een scherpe grens te trekken valt tussen gestoord en niet gestoord, maar anderzijds wordt op het terrein van de persoonlijkheidsstoornis gesproken van trekken in de persoon, zoals de neiging zich afhankelijk te maken van anderen (bij de afhankelijke persoonlijkheidsstoornis), een neiging zich groots te voelen (bij de narcistische persoonlijkheidsstoornis) enz. Dit zijn neigingen die zich ook binnen het spectrum van de normaliteit voordoen. Tegen over het begrip van de autonomie van het handelingssubject en diens zelfbeschikkingsmacht binnen het recht, vinden wij binnen de psychiatrie het begrip van de wezenlijke bepaaldheid van het handelen van het subject. Daarbij komt dat mensen - evident gestoord of niet - vaak niet weten wat zij doen in de bredere zin. Zij hebben bijvoorbeeld geen zicht op hun afhankelijkheid en kunnen zich al zeer onafhankelijk presenteren, of zij verbergen hun eigen grandiositeitsgedachten voor anderen en zichzelf. Dit is zelfs de gebruikelijke gang van zaken. Mensen met grandiositeitsproblematiek beleven deze veelal niet als zodanig maar beleven zich eerder als de pechvogel die met zoveel domme mensen moet omgaan.Het vermogen tot inzicht wordt zo binnen de psychiatrie niet betwist maar het bereik wordt wel gelimiteerd: mensen zijn verdeeld, zij willen dit én dat, maar hebben vanwege de verdeeldheid soms weinig zicht op wat zij willen. Het gevolg is dat tenslotte ook het begrip van verantwoordelijkheid - naast de autonomie en het vermogen tot inzicht - niet ongeclausuleerd aanvaardbaar lijkt binnen de psychiatrie, zoals dit binnen het recht in beginsel het geval is. Het psychiatrische mensbeeld is derhalve gecentreerd rond de noties van de bepaaldheid van het gedrag, de beperktheid van inzicht en de complexiteit van de verantwoordelijkheid voor zover die toegeschreven kan worden. Hieruit blijkt echter tevens dat ook in de psychiatrie een mensbeeld, een visie op de menselijke werkelijkheid fungeert, zoals dat ook in het recht het geval is, al verschillen de beide mensbeelden onderling onmiskenbaar. 


\section{Tegenstellingen in de praktijk}

De tegenstellingen die er zo tussen het psychiatrische en juridische mensbeeld bestaan doen zich ook op het vlak van de praktijk gelden. Het lijdt geen twijfel dat het begrip van de autonomie een centrale waarde is in het recht. Dit komt tot uiting in de strafbaarstellingen zelf, die tot doel hebben het leven en het eigendom, dat wil zeggen de sfeer van het zijn van de persoon (het lichaam) en de sfeer van zijn wijze van uitdrukking (het eigendom) te beschermen. Hieraan zijn dan nog toe te voegen de klassieke vrijheidsrechten en de strafvorderlijke bepalingen die tot doel hebben de rechtsbescherming van de burger jegens de overheid te optimaliseren, uiteraard met inachtneming van de marges die door de eisen van instrumentaliteit en doeltreffendheid zijn gesteld. De moderne verdragen met het accent op de bescherming van wat de mensenrechten worden genoemd, hebben dit accent op de waarde van de autonomie de laatste vijftig jaar nog versterkt. Dit heeft geleid tot wetgeving waarin de notie van de autonomie, van de zelfbeschikkingsmacht, niet als een feitelijk gegeven maar als een te behouden waarde, centraal stond. Men denke bijvoorbeeld aan de BOPZ-wet, maar ook het nieuwe jeugdstrafrecht, de recente Penitentiaire Beginselenwet, Beginselenwet TBS enz. Als rechtsgrond voor ingrijpen in het BOPZ-recht heeft het bestwilcriterium bijvoorbeeld moeten plaatsmaken voor het gevaarscriterium. Weliswaar kan het gevaarscriterium nauw of breder uitgelegd worden, in welks laatste geval het weer raakt aan het bestwilcriterium, maar dit neemt niet weg dat het gevaar voor anderen (of zichzelf) het uiteindelijke referentiepunt is en niet het vermeend beter weten van de behandelaar of de samenleving. Het schadebeginsel in de zin van Mill legitimeert ingrijpen maar beperkt dit ook. Wat zich aldus heeft doorgezet op de verschillende rechtsterreinen is de dominantie van de liberale moraal, zoals die ook de laatste twee eeuwen op het vlak van de politieke theorie de dominante moraal is geweest.

Het gevolg hiervan is een toename van spanningen tussen psychiatrie en het recht en respectievelijk tussen hun vertolkers. De externe toenemende juridische regulering van het psychiatrisch handelen beperkt het bereik ervan: niet alles mag meer wat kan. Dit doet zich voor op het gehele veld van de geestelijke gezondheidszorg. Vanwege de aangescherpte rechtspositie van patiënten in psychiatrische ziekenhuizen en verpleegtehuizen, is bij inper- 
kende maatregelen instemming van de patiënt of van diens belangenbehartiger vereist, en dit vergt tijd en overleg, wat tot ergernis kan leiden bij hulpverleners met een meer paternalistische achtergrond. Hetzelfde conflict kan ook ernstiger vormen aannemen omdat zich in de praktijk, als gevolg van juridische inperking, schrijnende situaties kunnen voordoen. In psychiatrische inrichtingen vertoeven bijvoorbeeld mensen die gedwongen zijn opgenomen - vanwege gevaar dat op grond van een stoornis jegens anderen of zichzelf uitgaat - maar die daarvoor, hoewel zij lijden aan een ernstige vorm van geestesziekte, niet of slechts in beperkte mate behandeld mogen worden indien zij deze behandeling afwijzen, tenzij zich een gevaar voordoet dat niet op andere wijze af te wenden is, en dat ernstiger moet zijn dan het gevaar waarvoor zij opgenomen zijn. Het is dus niet of slechts beperkt toegestaan dat de medicus de patiënt die op grond van zijn lijden - vanwege wat men een ontbrekend ziekte-inzicht noemt - de behandeling voor dit lijden afwijst, en die vaak ook nog subjectief lijdt, behandelt voor dit lijden. De behandelaar of verzorger kan zo door een kwellend besef van machteloosheid overvallen worden, temeer daar de mogelijkheid bestaat dat in sommige gevallen een gedwongen medicatie het lijden, minstens tijdelijk, zou verlichten.

In dat geval kan de juridische bemoeienis met de psychiatrie als extern aan de psychiatrie of zelfs als wezensvreemd eraan ervaren worden. Als dit zo zou zijn, heeft dat vergaande consequenties. Voorzover dat het geval is, ontstaat er niet alleen een conflict tussen de psychiatrie en juridische regelgeving, maar tussen de psychiatrie en de moderne samenleving in haar geheel, aangezien de juridische regelgeving een concretisering biedt van het respect voor de autonomie van de persoon. Het zou dan gaan om een conflict tussen de psychiatrie en een toch wel een zeer centrale waarde uit de moderne samenleving.

\section{Gemeenschappelijke aspecten van het juridisch en psychiatrische mensbeeld}

Daar staat tegenover dat de psychiatrie ook heel goed open kan staan voor deze waarde, voorzover de psychiatrie zelf kan inzien dat respect voor de autonomie - ook al zou zij deze inhoudelijk anders invullen dan binnen de liberale ethiek wel gebeurt - in de behandeling belangrijk is. In de vroegere inrichtingspsychiatrie was de patiënt toch in vrij sterke mate overgeleverd aan de relatieve willekeur van de staf, zonder dat er een mogelijkheid bestond de staf zelf ter verantwoording te roepen. In een zogeheten totaalinstituut is er geen 'gat', is er geen derde termen, is alles geregeld of 'bevolen'. 
Zo'n instituut fungeert als een almachtige, alleswetende ander. In zo'n situatie impliceert de introductie van rechtsposities het besef dat er posities zijn waaraan rechten en plichten zijn verbonden. Juridiseren impliceert zo de introductie van een 'derde term': niet alles is meer afhankelijk van een groot alwetend oog. Juridisering gaat zo de perversie tegen die eigen is aan totaalinstituten met hun machts- en afhankelijkheidsrelaties. De rechtsposities bevorderen zo de waarde van de zelfbeschikkingsmacht, van de autonomie. Zo is de psychiatrie zelf open komen te staan voor deze waarde, zoals die in haar veld is ingevoerd door het recht. Maar deze waarde ligt ten diepste besloten in het psychiatrisch project als zodanig, voorzover daar ook de waarde van de autonomie fungeert. Men heeft zelf oog gekregen voor het belang voor de geestelijke gezondheid van de mogelijkheid tot zelfbepaling, in de zin van een verminderde afhankelijkheid van anderen en wat die verlangen. Zulks geldt ook voor de waarde van het vermogen tot inzicht. Ook al is dit vermogen tot inzicht, volgens de psychiatrie, beperkt, dit limiteert niet het belang. Inzicht vergroot immers de mogelijkheid tot afstandneming, en daarmee ook weer die van zelfbepaling. Zo komt tenslotte het begrip verantwoordelijkheid naar voren. Geestelijke gezondheid kan immers omschreven worden als het vermogen verantwoordelijkheid te dragen voor het doen en laten, gegrond als dit vermogen is in het vermogen tot inzicht en tot zelfbepaling - in meer of mindere mate.

\section{Innerlijke vrijheid}

Hieruit blijkt dat het mensbeeld van de psychiatrie en het recht op het eerste gezicht weliswaar sterk uiteen lopen, maar dat zij bij nadere beschouwing uiteindelijk nauw verwant zijn. Vermogen tot inzicht en zelfbeschikkingsmacht leiden naar het vermogen verantwoordelijkheid te dragen. Het mensbeeld binnen psychiatrie en recht impliceert in beide gevallen de notie van verantwoordelijkheid, en daarmee uiteindelijk: vrijheid. Het is immers niet redelijk iemand verantwoordelijk te houden voor zijn daden als hem geen enkele vrijheid is gegeven in zijn daden. Het gaat bij deze vrijheid niet om de publieke of uitwendige vrijheid, maar de inwendige vrijheid. En die inwendige vrijheid veronderstelt dan weer het vermogen tot inzicht (tot overdenken en gevoelsmatig verwerken) en het vermogen tot zelfbeschikking, weten te handelen volgens het eigen intellectuele en emotionele inzicht. 
Uiteindelijk gaat het hier om de conceptie van een menselijke persoon als een wezen dat begiftigd is met de praktische rede. Het is een oude conceptie die teruggaat op Aristoteles welke in de laatste decennia weer naar voren is getreden. Hij is naar voren getreden omdat in deze conceptie de gesitueerdheid van de menselijke vrijheid zo goed tot uitdrukking komt. Menselijke vrijheid is niet gelegen in het onttrokken zijn aan de wereld van de bepaaldheid, maar is daarin verworteld. De menselijke vrijheid is dus gegrondvest in de vermogens tot overleg en zelfbepaling, welke het dragen van verantwoordelijkheid mogelijk maken, omdat de mens aangesproken kan worden op de keuzes die hij in zijn overleg, in zijn praktisch redeneren, heeft gemaakt. Omdat het menselijk handelen altijd situatiegebonden is, is de menselijke handelingsvrijheid evenzeer een situatief gebonden vrijheid. Het situatiegebonden karakter van de aldus beperkte vrijheid maakt tevens dat menselijke vrijheid een geworpen vrijheid is, omdat vrijheid zich moet manifesteren in een situatie die de mens deels niet heeft verkozen maar waarin hij naar de woorden van de hedendaagse hermeneutische filosofie is 'geworpen'. Dit neemt niet weg dat aan de persoon de mogelijkheid van overleg steeds gegeven is, zodat hij de onvrijheid die medegegeven is met het geworpen zijn in een bepaalde situatie, deels kan overschrijden. Precies daarin is de aan de menselijke situatie gebonden handelingsvrijheid gelegen, die het de persoon vervolgens tevens mogelijk maakt een zekere mate van verantwoordelijkheid te dragen.

\section{Divergenties}

Zo hebben psychiatrie en recht basaal een gemeenschappelijk mensbeeld gemeen, al lopen de specificaties uiteen. Het recht stelt iemand in beginsel verantwoordelijk voor zijn daden en het handelingssubject is bijgevolg vatbaar voor toerekening. Wel zijn er factoren denkbaar die in het handelingssubject zelf gelegen zijn die maken dat de vatbaarheid voor toerekening beperkt is of opgeheven. Deze eventuele factoren beperken de innerlijke vrijheid of heffen haar op, zoals het geval is bij, bijvoorbeeld verminderde toerekeningsvatbaarheid of ontoerekeningsvatbaarheid, vanuit de gedachte dat een psychische stoornis de inwendige vrijheid beperkt. Zo is het psychiatrische begrip van stoornis te zien als een psychiatrische vormgeving van deze notie van opgeheven of beperkte inwendige vrijheid (en daarmee samenlopend: autonomie, vermogen tot inzicht, vermogen tot het dragen van 
verantwoordelijkheid), zoals het juridische begrip van toerekeningsvatbaarheid een juridische specificatie inhoudt van dezelfde kernbetekenissen. Zo lopen het mensbeeld van psychiatrie en recht deels uitéén in de inhoudelijke invulling van de innerlijke vrijheid die vanuit de psychiatrie altijd als beperkt wordt gezien, en die vanuit het recht wordt gemaximaliseerd hoewel daar ook uiteraard grenzen worden erkend.Deze taxatieverschillen nemen niet weg dat het gaat om taxaties binnen één veld: het veld van verantwoordelijkheid, vermogen tot inzicht, autonomie, innerlijke vrijheid. Dit betekenisveld vormt dan ook bij alle divergentie het gemeenschappelijke mensbeeld van psychiatrie en recht.

\section{Het hermeneutische perspectief}

Wel dient er hier de kanttekening bij gemaakt te worden dat het gaat om de psychiatrie in haar hermeneutische aspect, en niet om een psychiatrie waarin de mens gezien wordt als een complex informatieverwerkend systeem. Het gaat hierbij niet om de tegenstelling tussen het eventuele belang van biologische versus psychologische factoren maar om het conceptuele kader. Niemand zal het belang van biologische factoren, de lichamelijke laag in het menselijk bestaan ontkennen. De vraag is echter of gewerkt en gedacht wordt vanuit een kader waar binnen ruimte is voor de menselijke persoon in zijn gesitueerde vrijheid of dat die ruimte er uiteindelijk niet is, omdat het menselijk gedrag in dit laatste geval opgevat wordt als een resultante van interne en externe causale factoren, die zich instrumenteel laten beheersen.

Het gaat ten aanzien van het recht evenzeer om het hermeneutische aspect daarvan. Wanneer er geen conceptuele ruimte is voor de menselijke persoon, met zijn innerlijke vrijheid en autonomie, blijft voor het recht alleen de instrumentele zijde over. Biologisme in de psychiatrie en instrumentalisme in het recht zijn dan elkaars pendant. Het gaat hierbij uiteraard niet om de waarde van het instrument als zodanig maar om de verabsolutering daarvan, wanneer de instrumentele dimensie niet meer omvat wordt door de hermeneutiek.

Hiermee is het hermeneutische perspectief als het uiteindelijk omvattende gesteld, zowel ten aanzien van de psychiatrie als het recht. Het gaat in bredere zin om een pleit voor de hermeneutische traditie waar gewaar-schuwd wordt tegen de overwoekering van de dimensie van 'zin' door de instrumentele rationaliteit - hoewel die laatste uiteraard haar recht heeft - zoals op 
uiteenlopende wijze geschiedt door Habermas, Gadamer, Apel en vele anderen.

\section{Nogmaals: de praktijk}

Het gaat er uiteindelijk om deze twee perspectieven ook in de praktijk te laten gelden: het perspectief van de tegenstelling tussen psychiatrie en recht enerzijds, en dat van het gemeenschappelijke mensbeeld, en de gemeenschappelijk gedeelde waarden anderzijds. Wanneer de onderlinge verhouding tussen beide disciplines zo opgevat worden, zijn spanningsmogelijkheden gegeven maar is er tevens uitzicht op verstandhouding. Het spanningsveld komt in het bijzonder tot uiting in de spanning die er is tussen dwangverpleging en dwangbehandeling (zoals die zich eerstens binnen de TBS voordoet).Het centrale punt is daarbij dat de TBS slechts een dwangverpleging heeft te bieden met de daaraan inherente inperking van de bewegingsvrijheid maar zich zo heeft omgevormd dat het om een dwangbehandeling gaat. De TBS-maatregel zou dan iets afdwingen wat door de maatregel zelf, die slechts strekt tot verpleging op grond van gevaar wegens een stoornis, niet wordt gelegitimeerd. Vanuit juridisch perspectief is dit kwestieus, vanuit psychiatrisch perspectief is deze gang van zaken - een zekere vorm van vervloeiing tussen verpleging en behandeling - echter praktisch gezien nauwelijks te vermijden. De oplossing van deze tegenstelling zou hierin liggen dat men bij de oplegging van neen TBS zich vergewist van enigerlei vorm van instemming van de betrokkene, ook al zijn voor hem hierbij de marges van vrijheid, van uitwendige vrijheid in dit geval, gering. Hetzelfde punt doet zich voor bij toepassing van gedwongen behandeling in engere zin, en wel dwangmedicatie binnen het BOPZ-recht (en ook TBSrecht). Gedwongen medicatie is in uiterste geval toegestaan wanneer de betrokkene op grond van zijn stoornis een gevaar vormt voor anderen of zichzelf, waarbij dit gevaar groter dient te zijn dan waarvoor hij opgenomen is (binnen het BOPZ-recht) en niet op andere manieren afgewend kan worden. Ook in dit geval lijkt het goed om zoveel mogelijk te streven naar instemming van de betrokkene, afgezien van de vraag hoe ruim de marges genomen worden wil men tot toepassing van dwangmedicatie overgaan. Ook hier lijkt het goed zoveel mogelijk een beroep te doen op de eigen verantwoordelijkheid van de betrokkenen, zodat de betrokkene zoveel als mogelijk is medeverantwoordelijkheid draagt voor zijn eigen behandeling. Hierbij geldt niet alleen het praktische punt dat men met de betrokkene ook 'verder' moet en dat dwangmedicatie vaak een zware hypotheek legt op het verdere traject, maar telt ook het uitgangspunt dat het vanuit psychiatrisch perspec- 
tief goed is de eigen verantwoordelijkheid te maximaliseren, waartoe het recht op zijn beurt uitnodigt.

\section{Nogmaals: autonomie}

Het centrale gemeenschappelijke begrip dat steeds weer naar voren komt, is het beroep op de eigen verantwoordelijkheid, zoals deze weer teruggaat op de zelfbeschikkingsmacht ofwel autonomie. Dit blijkt zo de centrale notie te zijn, binnen het recht voor zover dit uiteindelijk gedragen wordt door de liberale ethiek, zoals deze sedert de Verlichting de dominante ethiek geworden is op het vlak van de vormgeving van de samenleving; en binnen de psychiatrie waar de geestelijke gezondheid omschreven wordt als toenemende mogelijkheid tot zelfbepaling, individuatie, groei van autonomie.

Toch is deze notie onder toenemende kritiek komen te staan. Het liberale mensbeeld van het zelfbeschikkende, autonome, geïsoleerd gedachte individu wordt binnen deze kritiek als werkelijkheidsvreemd opgevat. Het atomistische persoonsbegrip, waar de mens wordt opgevat als individu dat slechts met anderen formele en daarna zakelijke betrekkingen in contractuele zin onderhoudt, wordt dan verworpen. Deze kritiek wordt verwoord vanuit het communitarisme of gemeenschapsdenken.

Een uitweg uit deze kritiek wordt gevormd door een 'contrafactische' procedurele opvatting van autonomie. In dat geval wordt, zoals bij Rawls, gesteld dat wij mensen slechts beschouwen als waren zij een oorsprong van zin, en van autonoom handelen, terwijl dat in de werkelijkheid in het geheel niet het geval hoeft te zijn. De waarde van de autonomie wordt losgekoppeld van de eventuele werkelijkheid ervan. Autonomie is dan alleen een begrip uit de sociale ethiek en politieke theorie. Hoewel deze procedurele route aantrekkelijke kanten heeft, is het resultaat toch niet bevredigend. Men zou dan de mens eventueel autonomie toeschrijven zonder dat hij daarover feitelijk beschikt. Hij zou bijgevolg ook verantwoordelijk gehouden kunnen worden voor daden waarvoor hij eventueel geen verantwoordelijkheid in feitelijke zin kan dragen. Het lijkt derhalve beter te erkennen dat de liberale ethiek uiteindelijk gedragen wordt door een mensbeeld, door een visie op de werkelijkheid van de mens. Dit wil niet zeggen dat het liberale mensbeeld geen nuancering verdraagt. De kritiek zoals die door het communitarisme, het gemeenschapsdenken is verwoord op het atomistische karakter van dit mensbeeld lijkt terzake. De identiteit van een persoon is niet slechts formeel 
maar wordt inhoudelijk bepaald door de omstandigheden en de veelheid van rollen die hij speelt. Zo bestaat iemands identiteit ook uit het verhaal dat hij vertelt en dat over hem verteld wordt en deze 'narratieve' identiteit wordt weer gedragen door de verhalen die in een gemeenschap leven. Anders uitgedrukt: autonomie, zelfbeschikkingsmacht, sluit afhankelijkheid van anderen niet uit. Men kan zelfs zeggen dat autonomie met daarbij inbegrepen verantwoordelijkheid en vrijheid, afhankelijkheid juist insluit. Wij kwamen dat idee al tegen in het begrip van 'gesitueerde vrijheid', van het gegeven dat vrijheid niet onttrokkenheid aan de bepaaldheid van een situatie inhoudt, maar dat vrijheid zich alleen in een situatie kan manifesteren.

Deze afhankelijkheid is ook weer niet het laatste woord. Dat zou in strijd zijn met de grondgedachte ten aanzien van de mens zoals die ontvouwd is. Afhankelijkheid heft vrijheid niet op: menselijke vrijheid is het vermogen de gegeven situatie te overdenken, gevoelsmatig te verwerken en zo te transcenderen. Afhankelijkheid van anderen en van de situatie heft zo ook de verantwoordelijkheid niet op, omdat men in de afstandneming ten opzichte van de situatie, in de overdenking en emotionele verwerking, ook verantwoordelijkheid draagt voor de situatie en de eigen afhankelijkheid.

Het gaat hierbij om toedrachten die deels nog wel juridiseerbaar of psychiatriseerbaar zijn, zoals het geval is ten aanzien van de culpa in causaproblematiek, waar het kernthema is de verantwoordelijkheid voor de eigen afhankelijkheid. Het gaat hierbij ook om toedrachten die niet meer juridiseerbaar of psychiatriseerbaar zijn, zoals de verantwoordelijkheid voor de levensloop of de basale keuzes die daarin gemaakt zijn.

Zo zijn psychiatrie en recht beide verworteld in een basale deels gemeenschappelijke mensvisie die enerzijds onderlinge verstandhouding mogelijk maakt maar ook spanningen kan veroorzaken. 